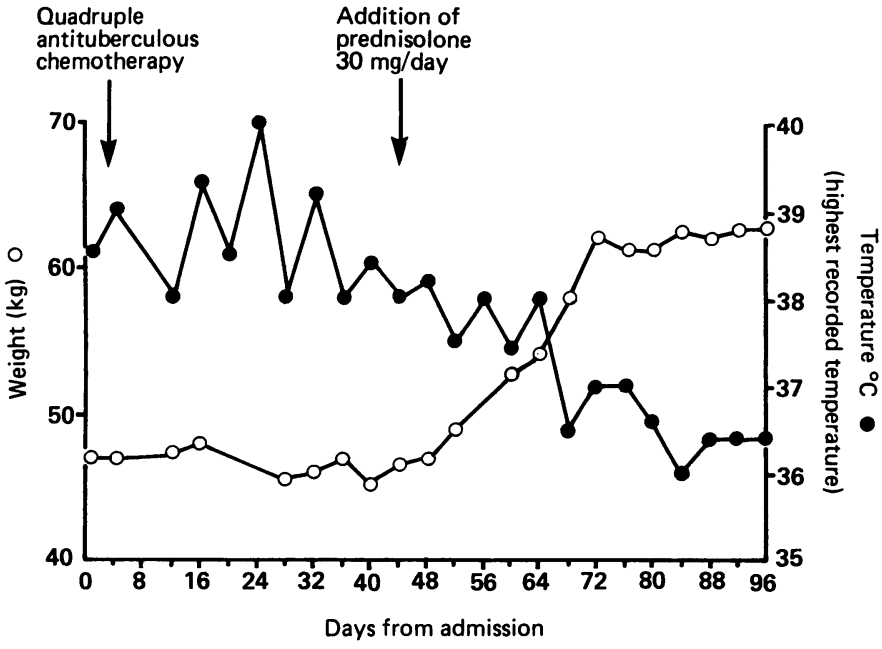

Temperature and weight chart before and after the introduction of corticosteroids.

tuberculosis quadruple therapy alone proved ineffective, even though the organisms were fully sensitive to the drugs. Added corticosteroids, however, achieved a dramatic improvement leading to cure. If the patient had not had HIV antibodies we would have used steroids much earlier in the illness. We were inhibited firstly by the possibility that we were dealing with an atypical mycobacterium with multiple drug resistance and secondly by the apparent illogicality of using steroids in a patient already immunocompromised. (The negative tuberculin reaction and the absence of granuloma formation certainly supported an assumption of impaired cell mediated responses.)

Evidence has recently been presented that corticosteroids may dramatically improve the outcome in patients with AIDS and severe Pneumocystis carinii pneumonia. ${ }^{5}$ The response to steroids in our patient suggests that corticosteroids may have a part to play in some other infections in patients with AIDS or AIDS related complex.

1 Pitchenik AE, Cole C, Russell BW, Fischl MA, Spira TJ, Snider DE Jr. Tuberculosis, atypical mycobacteriosis, and the acquired immunodeficiency syndrome among Haitian and non-Haitian patients in south Florida. Ann Intern Med 1984;101:641-5.

2 Doble N, Hykin P, Shaw R, Keal EE. Pulmonary Mycobacterium tuberculosis in acquired immunodeficiency syndrome. BrMed $\mathcal{f}$ 1985;291:849-50.

3 Crompton GK. Steroids in respiratory disease. Brf Hosp Med 1982;28:340-8.

4 Scully RE, Mark EJ, McNeely BU. Case 2-1986. Case records of the Massachusetts General Hospital. $N$ Engl f Med 1986;314:167-74.

5 MacFadden DK, Edelson JD, Hyland RH, Rodriguez CH, Inouye T, Rebuck AS. Corticosteroids as adjunctive therapy in treatment of Pneumocystis carinii in patients with acquired immunodeficiency syndrome. Lancet 1987; ;:1477-9.

(Accepted 15 October 1987)

Department of Chest Medicine, St Mary's Wing, Whittington Hospital, London N19

T MASUD, MA, MB, senior house officer

E KEMP, MB, BS, senior house officer

Correspondence to: DrT Masud, Department of Dermatology, St Bartholomew's Hospital, London EClA 7BE.

\section{Transvaginal ultrasound in suspected ectopic pregnancy}

Transabdominal ultrasound is performed in most suspected ectopic pregnancies. Its main value lies in ruling out intrauterine pregnancy. The appearance of the adnexa with ectopics is rarely diagnostic, as an extrauterine gestational sac and fetus are seen in fewer than $5 \%$ of cases. ${ }^{1}$

After experience of transvaginal scanning in infertility, with its superior quality and greater acceptability to patients, we have broadened its application to investigate gynaecological emergencies. We report its use in assessing suspected ectopic pregnancies.

\section{Case reports}

Case 1-A 30 year old primigravida presented with pain in the lower abdomen and vaginal bleeding at seven weeks' amenorrhoea. The bladder was emptied for bedside testing for human chorionic gonadotrophin with a urine monoclonal antibody enzyme immunoassay (Abbott Test Pack, Abbott Laboratories, North Chicago IL 60064), which detects urinary $\beta$ human chorionic gonadotrophin with a sensitivity of $50 \mathrm{mIU} / \mathrm{ml} .^{2}$ The result was positive. Transvaginal ultrasound was performed with a Diasonics DRF200 7.5 MHz mechanical sector transducer $\left(95^{\circ}\right.$ field of view, $8 \mathrm{~cm}$ depth of field). The probe, inserted in a condom with coupling gel on either side, was introduced with the patient in the lithotomy position. Thick echogenic midline uterine echoes suggested a decidual reaction, and a 3.5 $\mathrm{cm}$ gestational sac containing a fetal pole was seen in the left tubal ampulla. Both ovaries were normal. Free fluid in the cul de sac contained echogenic debris, which "floated" on pressing in with the probe, suggesting a dependent clot. A leaking tubal pregnancy was confirmed at laparotomy.

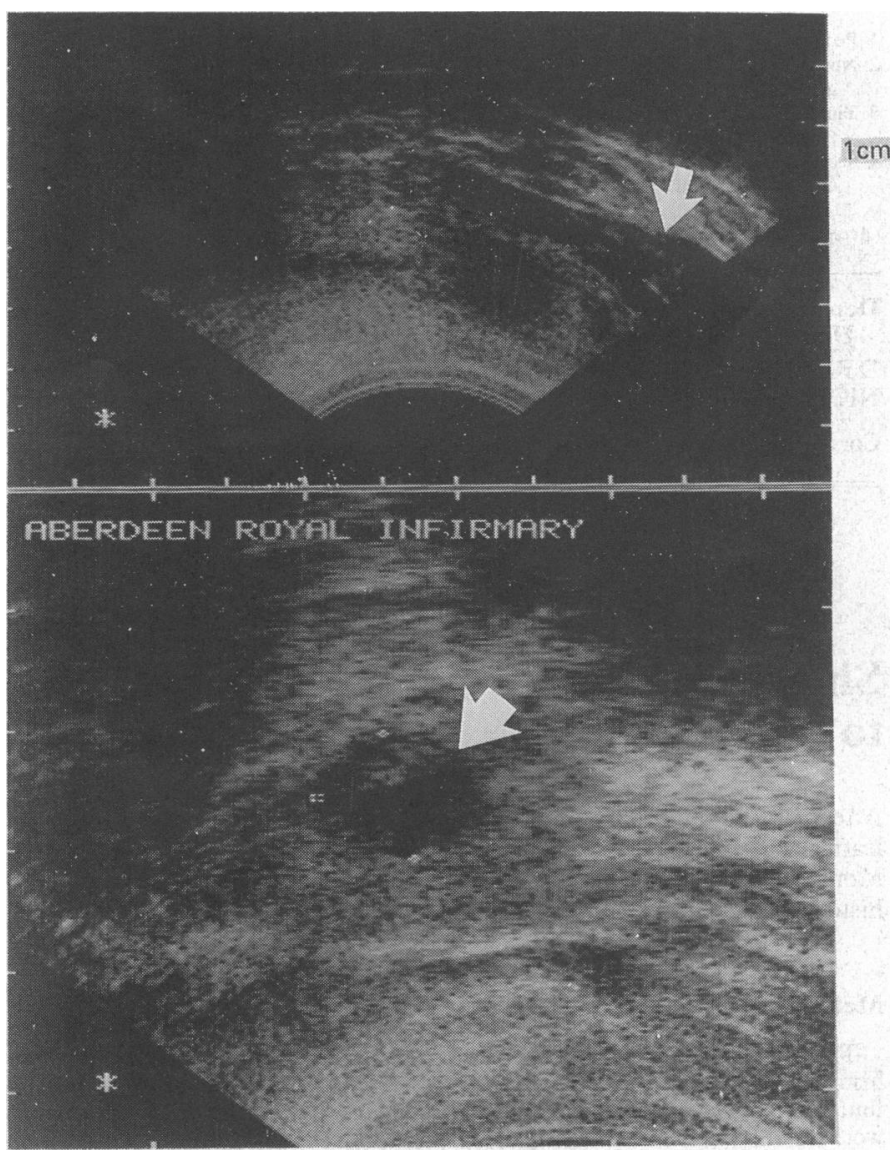

Top: Blood and clot in the cul de sac (case 1). Bottom: Gestational sac with fetal pole in the left tube (case 2).

Case 2-A 29 year old was admitted at six weeks' amenorrhoea with left sided pain. There was no bleeding, and urine testing showed the presence of human chorionic gonadotrophin. Transvaginal ultrasound with an empty bladder elicited tenderness over the left adnexa, where a $1 \cdot 2 \mathrm{~cm}$ gestational sac was seen. The uterus was empty. The diagnosis of left sided unruptured tubal ectopic pregnancy was substantiated at laparotomy within $1 \frac{1}{2}$ hours of admission.

\section{Comment}

The standard investigation of suspected ectopic pregnancy comprises, in order, vaginal examination, urinary pregnancy testing, and eventually transabdominal ultrasound. Urinary testing for human chorionic gonadotrophin and transvaginal ultrasound offer several advantages over the conventional approach

Firstly, unlike transabdominal scanning, the transvaginal approach does not require a full bladder, which is usually emptied on admission for analysing urinary human chorionic gonadotrophin. Time is not wasted while the patient fills her bladder, either by drinking, which may further postpone any surgical procedure while gastric emptying is awaited, or by intravenous infusions and diuretics, undesirable in the many women who are suspected of having an ectopic pregnancy but are later shown to have intrauterine pregnancies.

Secondly, the better quality of image than is seen with the transabdominal technique is partly due to higher frequencies and thus superior resolution. ${ }^{3}$ In addition, the transducer is not distanced from the pelvic structures to be 

tageous in obese patients. The vaginal probe can be manoeuvred in several planes and circumferentially around the cervix for the optimal visualisation of adnexal structures in the focal zone.

Finally, tenderness can be assessed with the probe under direct vision. It is possible to distinguish tubal from ovarian tenderness, which pelvic examination would have lumped together as "adnexal tenderness." Bimanual examination with its attendant risks of rupturing an ectopic pregnancy ${ }^{4}$ can thus be avoided.

In conclusion, transvaginal ultrasound offers distinct advantages over transabdominal scanning and may even render vaginal examination unnecessary.

1 Pederson JF. Ultrasonic scanning in suspected ectopic pregnancy. Br $\mathcal{F}$ Radiol 1980;53:1-4

2 Norman RJ, Reddi K, Patel F, Kemp M, Joubert SM. Sensitive urine tests and human chorionic

3 Timor-Tritsch IE, Rottem S. Transvaginal ultrasonographic study of the fallopian tube. Obstet Gynecol 1987;70:424-8.

4 Scott JS. Abortion. In: Dewhurst J, ed. Integrated obstetrics and gynaecology for postgraduates. 3rd ed. Oxford: Blackwell Scientific, 1981:226.

(Accepted 27 October 1987)

Department of Obstetrics and Gynaecology, Aberdeen Royal Infirmary and University of Aberdeen, Foresterhill, Aberdeen AB9 2ZD

D RENNIE UROUHART, MRCOG, registrar

Correspondence to: Dr Urquhart. visualised by the bladder and abdominal wall, which is especially advangonadotrophin secreted during ectopic pregnancy. Br Med f 1986;292:590-1.

NICHOLAS M FISK, FRACOG, DDU, lecturer and honorary senior registrar

The table shows that in leatherworkers who had suffered previous perinatal deaths only $29 \%$ had a history of previous pregnancy compared with $39 \%$ or $40 \%$ in all other groups. The 36 perinatal deaths in our previous report occurred in 34 pregnancies. ${ }^{1}$ The total number of "alive and well" pregnancies per woman was also much lower in the leatherworkers who had suffered previous perinatal deaths than in the other groups (table).

In these analyses the denominator used was the total number of women who had live births or deaths in the initial study. Non-responders in the subsequent interview were assumed in the analyses to have had no exposure to solvents or adhesives. The median number of years worked in the leather industry by women who had had previous perinatal deaths was 7.0 (range $<1$ to 20 ), whereas the median number of years in the group who had had live births was only 4.5 (range $<1$ to 10 ). Exposure to adhesives was reported in $62 \%$ of the perinatal death group and $50 \%$ in the live birth group. Similarly, work in the closing room of leatherwork factories, where solvents and glues are mainly used, was carried out by $71 \%$ of the perinatal death group and $61 \%$ of the live birth group.

In the group who had had previous perinatal deaths 16 women had had a further 25 pregnancies, giving a rate of 1.6 pregnancies per woman pregnant. In the group who had had live births nine women had had a further 10 pregnancies, giving a rate of $1 \cdot 1$ pregnancies per woman. There were no subsequent pregnancies that had led to a death or an abnormal baby in the live birth group, whereas there had been three deaths and one living birth with major congenital malformation in the perinatal death group.

\section{Comment}

Though the numbers in this reanalysis and resurvey are small, the findings from both the previous and subsequent obstetric histories seem to support the view that women in the boot and shoe industry may have been exposed to a fetotoxic agent.

We thank Dr R Randall for his advice on this work and Mrs Pamela Marshall for interviewing. The perinatal study is funded by the Leicestershire Health Authority.

1 Clarke M, Mason ES. Leatherwork: a possible hazard to reproduction. BrMed f 1985;290:1235-7. 2 McDonald AD, McDonald JC. Outcome of pregnancy in leatherworkers. Br Med $\mathcal{f} 1986 ; 292$. 979-81.

(Accepted 27 October 1987)

Department of Community Health, University of Leicester, Clinical Sciences Building, University Medical School, Leicester Royal Infirmary, Leicester LE2 7LX

MICHAEL CLARKE, DPH, FFCM, professor of epidemiology ELIZABETH S MASON, BSC, MPHIL, research associate

Correspondence and requests for reprints to: Professor Clarke.

The reanalysis was carried out in two parts. Firstly, we analysed the obstetric histories of the women studied before they were included in the initial study. The four groups were: leatherworkers who had suffered perinatal death, leatherworkers who had delivered live babies, other social class III (manual) women who had suffered perinatal death, and other social class III (manual) women who had delivered live babies. Secondly, in conjunction with the Health and Safety Executive, an employment nursing adviser interviewed all the leatherworkers, using a questionnaire designed to collect a complete occupational history together with details of any further pregnancies since their inclusion in the initial perinatal mortality survey. At the interview no particular emphasis was placed on either the obstetric history - that is, perinatal deaths or live births - or any particular occupation. In the main perinatal survey there was a $100 \%$ response, and in the subsequent interview the resposne rate was 28 of $34(82 \%)$ in the perinatal death group and 14 of $18(78 \%)$ in the live birth group. Almost all non-responders were those who had moved out of the area.

Previous obstetric histories in women leatherworkers and other social class III working women

\begin{tabular}{|c|c|c|c|c|}
\hline & \multicolumn{2}{|c|}{$\begin{array}{l}\text { Other social class III } \\
\text { manual workers }\end{array}$} & \multicolumn{2}{|c|}{ Leatherworkers } \\
\hline & Perinatal & Live & Perinatal & Live \\
\hline $\begin{array}{l}\text { No of women in study } \\
\text { No }(\%) \text { with history of any pregnancy } \\
\text { No of previous pregnancies: }\end{array}$ & $\begin{array}{c}87 \\
34(39)\end{array}$ & $\begin{array}{c}93 \\
37(40)\end{array}$ & $\begin{array}{c}34 \\
10(29)\end{array}$ & $\begin{array}{c}18 \\
7(39)\end{array}$ \\
\hline Alive and well & 39 & 43 & 7 & 9 \\
\hline Involuntary loss ${ }^{\star}$ & 19 & 17 & 7 & 4 \\
\hline Terminations & 8 & 10 & 1 & 0 \\
\hline Total & 66 & 70 & 15 & 13 \\
\hline $\begin{array}{l}\text { No of previous pregnancies per woman } \\
\text { No of previous pregnancies per woman }\end{array}$ & 0.8 & $0 \cdot 8$ & $0 \cdot 4$ & $0 \cdot 7$ \\
\hline $\begin{array}{l}\text { ever pregnant } \\
\text { Involuntary loss as } \% \text { of all previous }\end{array}$ & $1 \cdot 9$ & 1.9 & 1.5 & 1.9 \\
\hline pregnancies & 29 & 24 & 47 & 31 \\
\hline Alive and well pregnancies per woman & $0 \cdot 4$ & 0.5 & 0.2 & 0.5 \\
\hline
\end{tabular}

^Spontaneous abortions and perinatal deaths.
Prostatic tissue was obtained from 33 unselected patients after transurethral or retropubic prostatectomy. Specimens were processed within 30 minutes or stored at $4^{\circ} \mathrm{C}$ for up to 20 hours. Tissue $(1 \mathrm{~g})$ was washed ${ }^{3}$ and then minced with a sterile technique before being rolled on to heated blood agar plates $(5 \%$ horse blood) and blood agar plates with neomycin $(28 \mathrm{mg} / \mathrm{l})$. Heated blood agar plates were incubated at $37^{\circ} \mathrm{C}$ in $10 \%$ carbon dioxide, and blood agar plates with neomycin were incubated at $37^{\circ} \mathrm{C}$ anaerobically. The tissue was then transferred into $80 \mathrm{ml}$ Fastidious Anaerobe Broth (Lab M, Bury, Lancashire) and subcultured after two and seven days' incubation at $37^{\circ} \mathrm{C}$ on to the two types of plates. Anaerobic classified by an independent observer as benign or malignant on histological examination. Clinical information, including age, whether preoperative antibiotics had been given, and presence or absence of a catheter, was obtained retrospectively from hospital case notes.

Histological examination showed that nine of the 33 samples of prostatic tissue contained foci of carcinoma; the remaining 24 showed only benign prostatic hyperplasia. Six of the nine malignant specimens and none of the 24 benign specimens grew anaerobes $\left(\chi^{2}=19 \cdot 56, p<0 \cdot 001\right)$; in all six cases the specimens bacteria were identified by the methods of Holdeman et al. ${ }^{4}$ Routine sections were 